\title{
Peningkatan Kadar Ketoprofen Terdisolusi melalui Pembentukan Dispersi Padat menggunakan Polivinil Alkohol (PVA)
}

\section{(The Increasing of Dissolved Ketoprofen Concentration through Solid Dispersion Formation using Polyvinyl Alcohol (PVA))}

\author{
Asriana Sultan ${ }^{1}$, Nur Ida ${ }^{2}$, Isriany Ismail ${ }^{3}$ \\ ${ }^{1}$ Jurusan Farmasi, Fakultas MIPA, Universitas Tadulako, Palu-Sulawesi Tengah, 94118 \\ ${ }^{2}$ Program Studi Farmasi, Fakultas MIPA, Universitas Islam Makassar, Tamalanrea, Makassar-Sulawesi \\ Selatan, 90245 \\ ${ }^{3}$ Jurusan Farmasi, Fakultas Kedokteran dan Ilmu Kesehatan, Universitas Islam Negeri Alauddin Makassar, \\ Kabupaten Gowa-Sulawesi Selatan, 92113
}

Article Info:

Received: 14 March 2018

in revised form: 26 March 2018

Accepted: 30 March 2018

Available Online: 30 March 2018

Keywords:

Solid Dispersion

Physical Mixture

Dissolution

Ketoprofen

PVA

Corresponding Author:

Asriana Sultan

Jurusan Farmasi, FMIPA

Universitas Tadulako

Palu, 94118

Indonesia

Mobile : 081355528538

Email: asriana.sultan@untad.ac.id

\begin{abstract}
Ketoprofen is included in the Class II of Biopharmaceutical Classification System (BCS) which has low solubility. Low solubility will affect the dissolution rate and the dissolved concentration, so the absorption and bioavailability are low as well. Several studies have been conducted to improve the solubility and the dissolution of drugs from these group, such as by solid dispersion system. This study aims to determine the effect of polyvinyl alcohol (PVA) on the dissolved concentration of ketoprofen in solid dispersion and in physical mixture, and to decidethe optimum formula.Solid dispersion and physical mixture of ketoprofen - PVA were formulated with the ratio of 1:1, 1:2 and 1:4, and then compared with the standard ketoprofen. Evaluation of solid dispersion was performed by the intervention test of PVA as a matrix on the maximum wavelength of standard ketoprofen using a UV-Vis spectrophotometer and the dissolution test in artificial gastric fluid media without pepsin using a basket stirrer at $\mathrm{pH} \pm 1,2$, the temperature of $37 \pm 0.5^{\circ} \mathrm{C}$, and device speed of $50 \mathrm{rpm}$. The sample was collected at 10, 20,30,45, and 60 minutes. The amount of dissolved ketoprofen was determined by a UV-Vis spectrophotometer at a wavelength of $260 \mathrm{~nm}$. The results showed that there was no shifting on maximum wavelength point in both solid dispersions and physical mixtures. The dissolved ketoprofen concentration that was represented in solid dispersion was greater than in physical mixture and standard ketoprofen. The highest dissolved ketoprofen concentration was indicated in solid dispersion formula with the ratio of $1: 1$.
\end{abstract}

Copyright (C) 2019 JFG-UNTAD

This open access article is distributed under a Creative Commons Attribution (CC-BY-NC-SA) 4.0 International license.

How to cite (APA 6th Style):

Sultan, A., Ida, N., Ismail I. (2019). Peningkatan Kadar Ketoprofen Terdisolusi melalui Pembentukan Dispersi Padat menggunakan Polivinil Alkohol (PVA). Jurnal Farmasi Galenika : Galenika Journal of Pharmacy, 5(1), $43-48$. doi:10.22487/j24428744.2019.v5.i1.12096 


\begin{abstract}
ABSTRAK
Ketoprofen termasuk dalam golongan obat Biopharmaceutical Classification System (BCS) Kelas II yang memiliki kelarutan rendah. Obat dengan kelarutan rendah akan mempengaruhi laju disolusi dan kadar terdisolusinya dalam tubuh, sehingga absorpsi dan bioavailibilitasnya rendah pula. Beberapa penelitian telah dilakukan untuk memperbaiki kelarutan dan disolusi obat-obat dari golongan tersebut, seperti dengan cara pembuatan dispersi padat. Penelitian ini bertujuan untuk mengetahui pengaruh penggunaan polivinil alkohol (PVA) terhadap kadar ketoprofen yang terdisolusi dari dispersi padat dan campuran fisik serta menentukan formula yang optimum untuk meningkatkan kadar ketoprofen terdisolusi. Dispersi padat dan campuran fisik dari ketoprofen - PVA diformulasi dengan perbandingan 1:1, 1:2 dan 1:4, dengan pembanding ketoprofen baku. Evaluasi dispersi padat dilakukan melalu uji intervensi matriks PVA terhadap panjang gelombang maksimum ketoprofen baku dengan menggunakan spektrofotometer UV-Vis dan uji disolusi dalam media cairan lambung buatan tanpa pepsin menggunakan pengaduk keranjang pada $\mathrm{pH} \pm 1,2$, suhu $37 \pm 0,5^{\circ} \mathrm{C}$, dan kecepatan alat 50 rpm. Pengambilan larutan contoh dilakukan pada menit ke - 10, 20, 30, 45, dan 60. Jumlah ketoprofen yang terdisolusi ditetapkan dengan spektrofotometer UV-Vis pada panjang gelombang $260 \mathrm{~nm}$. Hasil penelitian menunjukkan bahwa tidak terjadi pergeseran panjang gelombang maksimum pada dispersi padat maupun campuran fisiknya. Kadar ketoprofen terdisolusi yang ditunjukkan dalam dispersi padat lebih besar dibanding campuran fisik dan ketoprofen baku. Kadar ketoprofen terdisolusi terbesar diperlihatkan oleh formula dispersi padat pada perbandingan 1:1.
\end{abstract}

Kata Kunci : dispersi padat, campuran fisik, disolusi, ketoprofen, PVA

\section{PENDAHULUAN}

Efek teraupetik suatu obat ditentukan oleh proses melepasnya bahan obat dalam cairan tubuh dan terabsorpsi ke dalam aliran darah. Suatu obat yang dapat diabsorbsi, pertama kali harus dapat terlarut (terdispersi molekuler) dalam cairan yang menjadi tempat obat tersebut akan diabsorpsi (Saifullah, 2008). Laju pelarutan obat-obat dalam saluran cerna akan mengendalikan laju absorpsi sistemik obat dan menjadi penentu bioavailibilitas obat. Jika suatu obat diabsorpsi secara sempurna setelah pelarutan, maka akan menghasilkan konsentrasi obat dalam plasma yang lebih tinggi (Shargel, 2005).

Noyes dan Whitney (1897) menunjukkan bahwa kelarutan obat dalam air merupakan faktor utama yang menentukan laju disolusi. Beberapa studi telah menunjukkan bahwa data kelarutan bahan obat dapat digunakan sebagai prediksi adanya kemungkinan masalah mengenai bioavailibilitas, yang merupakan suatu faktor pertimbangan dalam desain formulasi sediaan obat (Gennaro, 1990).

Obat-obat yang kelarutannya sangat kecil dalam air sering banyak menimbulkan masalah pada proses absorpsinya setelah obat diberikan, karena obat dapat diabsorpsi oleh tubuh bila sudah dalam bentuk terdistribusi secara molekular di tempat proses absorpsi berlangsung. Upaya mengatasinya antara lain dapat dilakukan melalui peningkatan kecepatan disolusinya.

Teknik alternatif yang digunakan seperti dispersi padat dapat digunakan untuk meningkatkan laju disolusi bahan obat dengan kelarutan yang buruk dan telah dibuktikan dapat meningkatkan jumlah obat terlarut pada daerah absorpsi yang secara konsekuen meningkatkan bioavailibilitas (Drooge, 2006). Sekiguchi dan Obi (1961) memperkenalkan teknik ini dengan tujuan untuk memperkecil ukuran partikel, meningkatkan laju disolusi, dan meningkatkan absorpsi obat yang tidak larut dalam air. Tahun 1965, konsep tersebut dikembangkan Tachibana dan Nakamura dengan menggunakan polivinilpirolidon (PVP) sebagai pembawa dan dispersi dibuat melalui metode pelarutan (Leuner, 2000 dan Serajuddin, 1999). Selain itu, Sekiguchi dan Obi menyatakan bahwa obat tidak hanya berada dalam bentuk campuran eutektik dalam bentuk mikrokristal, tetapi sebagai fraksi obat yang terdispersi molekular dalam matriks dalam suatu bentuk larutan padat (Chaudhari, 2006).

Perkembangan beberapa tahun terakhir memperkenalkan beberapa jenis polimer yang dapat mengontrol drug delivery. Polimer sintetik menjadi pilihan matriks untuk sistem dispersi padat karena sifatnya yang inert, peka, mengontrol pelepasan obat denga efektif, dan mudah terbiodegradasi. Berbagai 
polimer seperti, polietilenglikol (PEG),polivinilpirolidon (PVP), polivinilalkohol (PVA), dan beberapa poliaminoasid yang lain.

Ketoprofen atau asam 2-(3-benzoilfenil) propionat merupakan suatu obat anti inflamasi nonsteroid yang digunakan secara luas untuk mengurangi nyeri dan inflamasi yang disebabkan oleh beberapa kondisi seperti, osteoartritis dan reumatoid artritis dengan dosis 25 - $50 \mathrm{mg}$ dan mempunyai bioavailibilitas 90\% (Tan, 2003). Namun, ketoprofen praktis tidak larut dalam air, sehingga kecepatan disolusi dan ketersediaan hayatinya rendah (Parfitt, 1999). Oleh karena itu, ketoprofen menjadi salah satu objek yang penting untuk ditingkatkan bioavailibilitasnya pada pemberian oral melalui pembuatan obat dalam sistem dispersi padat.

Fikri Alatas, Sundani Nurono S., dan Sukmadjaja Asyarie (2006) telah melakukan penelitian untuk meningkatkan laju disolusi ketoprofen dengan menggunakan PEG 4000 sebagai pembawa dalam bentuk dispersi padat. Penelitian sebelumnya juga telah banyak dilakukan, seperti dispersi padat ketoprofen - PEG 6000 (Arias, 1995) dan Kollicoat IR dengan matriks PVA - PEG graft copolymer (Sandrien Janssens, 2006). Dispersi padat ketoprofen dengan matriks polimer PEG telah terbukti dapat meningkatkan laju disolusi ketoprofen. Berdasarkan hal tersebut, untuk menambah data valid dari dispersi padat ketoprofen, maka dalam penelitian ini akan dikembangkan pola dispersi padat dengan polimer lain yaitu PVA.Penelitian ini bertujuan untuk mengetahui pengaruh penggunaan PVA (tanpa kombinasi dengan polimer lain) untuk meningkatkan kadar ketoprofen terdisolusi dalam sistem dispersi padat dan menentukanformula dengan perbandingan ketoprofen - PVA yang paling optimum untuk meningkatkan kadar ketoprofen terdisolusi.

\section{METODE PENELITIAN}

\section{Alat dan Bahan}

Alat-alat yang digunakan dalam penelitian ini adalah alat uji disolusi (Erweka ${ }^{\circledR}$ DT6), spektrofotometer UV-Vis (Jenway $^{\circledR}$ 6505), timbangan digital (Citizen ${ }^{\circledR}$ MB 200), desikator, cawan petri, pipet volum, dan alat-alat gelas lainnya yang umum digunakan dalam laboratorium.

Bahan-bahan yang digunakan dalam penelitian ini adalah ketoprofen murni (baku) (MERCK ${ }^{\circledR}$ ), polivinil alkohol (PVA), $\mathrm{HCl}$ (р.a.), $\mathrm{Na}_{2} \mathrm{H}_{3} \mathrm{PO}_{4}$ (р.a.), kertas indikator $\mathrm{pH}$, dan alumunium foil.

\section{Metode}

\section{Formulasi Dispersi Padat dan Campuran Fisik Ketoprofen - PVA}

Tabel 1. Rancangan Formula Dispersi Padat dan Campuran Fisik Ketoprofen - PVA

\begin{tabular}{clc}
\hline No. & Rancangan Formula & Perbandingan \\
\hline 1. & Dispersi padat & $1: 1$ \\
& ketoprofen : PVA & $1: 2$ \\
\cline { 3 - 3 } & & $1: 4$ \\
\hline 2. & Campuran fisik & $1: 1$ \\
\cline { 2 - 2 } & ketoprofen : PVA & $1: 2$ \\
\hline
\end{tabular}

\section{Pembuatan Dispersi Padat Ketoprofen - PVA}

Dispersi padat ketoprofen - PVA dibuat dengan metode pelarutan dalam perbandingan ketoprofen PVA yaitu 1:1, 1:2, dan 1:4. PVA dilarutkan dalam air suling (1:5) dengan pemanasan diatas magnetik stirrer pada suhu $70^{\circ} \mathrm{C}$. Kemudian ketoprofen dilarutkan dalam etanol (96\% P) dan ditambahkan ke dalam larutan PVA. Campuran ketoprofen dan PVA tersebut diuapkan pelarutnya, kemudian disimpan dalam desikator berisi silika gel selama 21 hari. Setelah kering, selanjutnya diserbukkan dan diayak dengan ayakan nomor mesh 60 (Alatas, dkk, 2006).

\section{Pembuatan Campuran Fisik Ketoprofen - PVA}

Ketoprofen dan PVA masing-masing ditimbang sesuai dengan perbandingan yang diinginkan, kemudian dihaluskan dan diayak dengan ayakan nomor mesh 60. Hasil ayakan dicampur tanpa perlakuan khusus dengan perbandingan 1:1, 1:2, dan 1:4 (Janssens, et al, 2007).

\section{Evaluasi Dispersi Padat}

\section{Uji Intervensi}

Uji intervensi PVA dalam dispersi padat dilakukan dengan cara melarutkan 50 mg ketoprofen dalam 100 ml larutan dapar fosfat $\mathrm{pH}$ 7,4, kemudian dilakukan pengenceran hingga konsentrasi 10 bpj lalu ditentukan panjang gelombang maksimumnya (Alatas, dkk, 2006).

Pengenceran juga dilakukan terhadap dispersi padat ketoprofen - PVA yang mengandung $50 \mathrm{mg}$ ketoprofen dengan menggunakan cairan lambung buatan hingga konsentrasi 10 bpj, kemudian 
dilakukan pengukuran panjang gelombang maksimumnya (Alatas, dkk, 2006).

\section{Uji Disolusi}

Media disolusi yang disiapkanyaitu cairan lambung buatan tanpa pepsin yang dibuat dengan cara melarutkan 2,0 g NaCl P dalam 7,0 ml $\mathrm{HCl} P$ dan dicukupkan volume dengan akuades hingga 100,0 ml. Diukur larutan pada pH 1,2 (Anonim, 1979).

Uji disolusi dilakukan menggunakan pengaduk keranjang yaitu dengan cara masing-masing dispersi padat dan campuran fisik ketoprofen - PVA yang setara dengan $50 \mathrm{mg}$ ketoprofen dimasukkan dalam keranjang disolusi, kemudian keranjang dicelupkan ke dalam labu disolusi yang berisi $900 \mathrm{ml}$ media dengan suhu $37 \pm 0,5^{\circ} \mathrm{C}$. Selanjutnya keranjang diputar dengan kecepatan 50 putaran per menit. Pengambilan sampel larutan dilakukan pada menit ke - 10, 20, 30, 45, dan 60 masing-masing sebanyak 10 ml. Setiap pengambilan sampel larutan, segera ditambahkan kembali ke dalam labu disolusi yang berisi larutan media disolusi yang baru dengan volume dan suhu yang sama (Anonim, 1995).

\section{Penetapan Kadar Hasil Uji Disolusi}

Satu seri pengenceran larutan ketoprofen dibuat dalam larutan dapar fosfat $\mathrm{pH}$ 7,4 dengan konsentrasi 2, 3, 4, 5, 6, 10, dan $20 \mathrm{bpj}$, kemudian masing-masing diukur serapannya pada panjang gelombang maksimum. Selanjutnya dibuat kurva antara serapan dengan konsentrasi.

Jumlah ketoprofen yang terdisolusi tiap satuan waktu tertentu ditentukan dengan mengukur serapan pada panjang gelombang maksimum dan dihitung kadarnya dengan menggunakan kurva baku.

\section{HASIL DAN PEMBAHASAN}

\section{Penentuan Panjang Gelombang Maksimum Ketoprofen}

Penentuan panjang gelombang maksimum ketoprofen dalam larutan dapar fosfat $\mathrm{pH}$ 7,4 memberi nilai serapan pada panjang gelombang maksimum $260 \mathrm{~nm}$.

\section{Pembuatan Kurva Baku Ketoprofen}

Hasil pembuatan kurva baku larutan ketoprofen dalam dapar fosfat $\mathrm{pH} 7,4$ diperoleh persamaan garis lurus $\mathrm{y}=0,0618+0,0126 \mathrm{x}$ dengan koefisien korelasi $r=0,998$.

\section{Hasil Uji Intervensi}

Hasil uji intervensi pembawa PVA terhadap panjang gelombang maksimum ketoprofen memperlihatkan bahwa dispersi padat serta campuran fisik ketoprofen - PVA tidak mengalami pergeseran panjang gelombang dan mempunyai nilai serapan yang relatif sama dengan ketoprofen baku yakni memberikan serapan pada panjang gelombang maksimum $260 \mathrm{~nm}$. Hasilnya dapat dilihat pada tabel 2.

Tabel 2.Uji Intervensi PVA

\begin{tabular}{cc}
\hline $\begin{array}{c}\text { Konsentrasi } \\
\text { Ketoprofen : PVA (bpj) }\end{array}$ & $\begin{array}{c}\text { Panjang } \\
\text { gelombang (nm) }\end{array}$ \\
\hline $10: 0$ & $260^{*}$ \\
\hline $10: 10$ & 260 \\
\hline $10: 20$ & 260 \\
\hline $10: 40$ & 260 \\
\hline
\end{tabular}

Keterangan :

* Perbandingan ketoprofen - PVA 10 : 0 (ketoprofen baku) diukur serapannya dalam larutan dapar fosfat $\mathrm{pH}$ 7,4

Tabel 3. Kadar Ketoprofen Terdisolusi per satuan waktu

\begin{tabular}{cccccccc}
\hline \multirow{2}{*}{ No. } & Sampel & Perbandingan & \multicolumn{5}{c}{ Kadar Ketoprofen Terdisolusi (\%) } \\
\cline { 3 - 7 } & & $\mathbf{1 0}$ & $\mathbf{2 0}$ & $\mathbf{3 0}$ & $\mathbf{4 5}$ & $\mathbf{6 0}$ \\
\hline 1. & $\begin{array}{c}\text { Ketoprofen baku } \\
\text { (ketoprofen : PVA) }\end{array}$ & $1: 0$ & 0,6 & 1,3 & 1,4 & 1,6 & 2,0 \\
\hline 2. & $\begin{array}{c}\text { Dispersi padat } \\
\text { ketoprofen : PVA }\end{array}$ & $1: 1$ & 19,5 & 26,1 & 26,3 & 26,5 & 26,6 \\
\cline { 2 - 7 } & $1: 2$ & 17,8 & 23,1 & 26,6 & 28,9 & 31,6 \\
\hline 3. & $\begin{array}{c}\text { Campuran fisik } \\
\text { ketoprofen : PVA }\end{array}$ & $1: 4$ & 13,3 & 18,2 & 22,8 & 26,5 & 28,8 \\
\cline { 2 - 7 } & $1: 1$ & 2,5 & 3,7 & 4,4 & 4,9 & 5,7 \\
\hline
\end{tabular}




\section{Hasil Uji Disolusi}

Hasil uji disolusi menunjukkan adanya perbedaan yang sangat signifikan antara dispersi padat dan campuran fisik dengan pembanding ketoprofen baku dalam meningkatkan kadar ketoprofen terdisolusi seperti terlihat pada gambar 1 . Penggunaan matriks PVA terlihat pengaruhnya dalam meningkatkan kadar ketoprofen terdisolusi yang ditunjukkan pada tabel 3 . Pembanding ketoprofen baku (tanpa penambahan PVA) menunjukkan kadar ketoprofen terdisolusi pada menit ke - 60 sebesar 2,0\% lebih kecil dibandingkan denganformula campuran fisikberkisar antara $5-6 \%$ dan formula dispersi padat berkisar antara sebesar 26 - 31\%. Kadar ketoprofen terdisolusi yang terbesar ditunjukkan oleh formula dispersi padat. Kondisi ini diasumsikan terjadi karena terbentuknya larutan padat diskontinyu ketoprofen PVA, yaitu ketoprofen dan matriks PVA sebagian tidak tercampur tetapi ketoprofen telah terdispersi secara molekuler, sehingga menghasilkan kadar ketoprofen terdisolusi yang lebih besar. Namun, penentuan tipe dispersi padat tersebut harus dilakukan pengujian lanjutan.

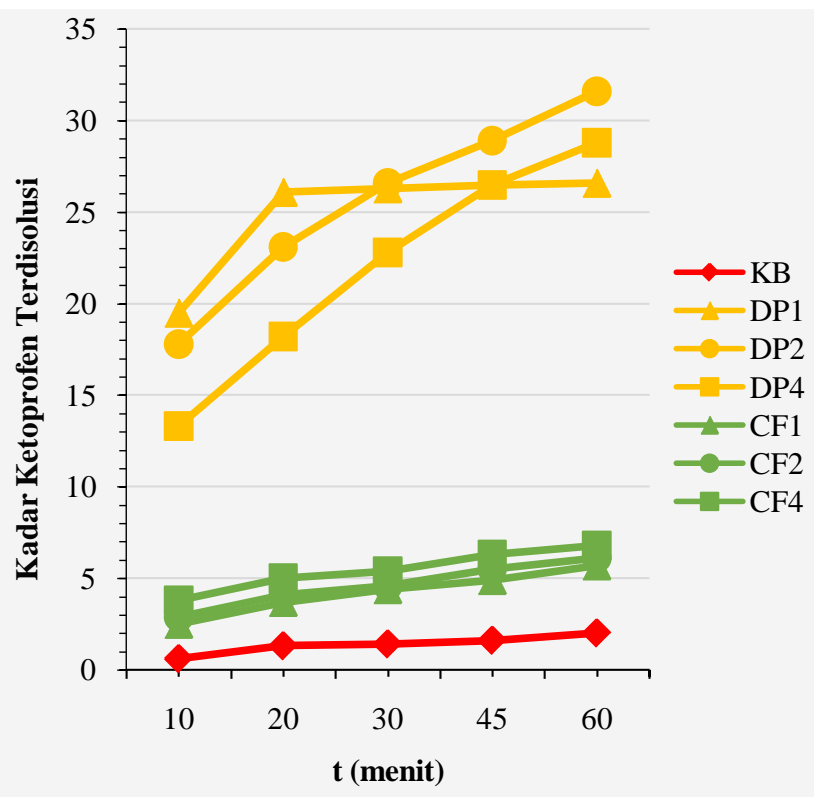

Gambar1.Hubungan kadar ketoprofen terdisolusi (\%) dengan waktu (menit). Ket. $\mathrm{KB}=$ ketoprofen baku, DP1 = dispersi padat 1:1, DP2 = dispersi padat 1:2, DP4 = dispersi padat 1:4, CF1 $=$ campuran fisik 1:1, CF2 = campuran fisik 1:2, CF4 = campuran fisik 1:4

Hasil rancangan acak lengkap (RAL) faktorial yang dilanjutkan dengan Uji Berat Nyata Terkecil (BNT) menunjukkan bahwa dispersi padat pada ketiga perbandingan tidak menunjukkan perbedaan yang signifikan, maka dapat disimpulkan bahwa formula dispersi padat ketoprofen - PVA pada perbandingan 1:1 memberikan kadar ketoprofen terdisolusi paling optimum dibandingkan dengan kadar ketoprofen baku yang terdisolusi tanpa penambahan PVA.

\section{KESIMPULAN}

Uji disolusi menunjukkan bahwa PVA dalam sistem dispersi padat dan campuran fisik dengan ketoprofen dapat meningkatkan kadar ketoprofen terdisolusidibandingkan dengan ketoprofen baku tanpa penambahan PVA. Formula yang optimum dihasilkan oleh dispersi padat ketoprofen - PVA pada perbandingan 1:1 dengan kadar ketoprofen yang terdisolusi sebesar $26,6 \%$.

\section{DAFTAR PUSTAKA}

Alatas, F., Nurono S. \& Asyarie, S. (2006). Pengaruh konsentrasi PEG 4000 terhadap laju disolusi ketoprofen dalam sistem dispersi padat ketoprofen - PEG 4000. Majalah Farmasi Indonesia, 17(2), 57-62.

Anonim. (1979). Farmakope Indonesia (edisi III). Jakarta, Departemen Kesehatan Republik Indonesia.

Anonim. (1995). Farmakope Indonesia (edisi IV). Jakarta, Departemen Kesehatan Republik Indonesia.

Arias, M.J., Ginos, J.M., Moyano, J.R., PorezMartinez, J.I., Rabasco, A.M. (1995). Influence of the preparation method of solid dispersions on their dissolution rate: study of triamterene-D-mannitol system. International Journal of Pharmaceutics, 123, 25-31.

Chaudhari, P.D. (2006). Current trends in solid dispersions techniques. Journal of Pharmainfo, 1.

Drooge, D.J. (2006). Production, stability, and dissolution of solid dispersions to improve the bioavailability of class II lipophilic drugs. Dissertation of Science, 13, 15 - 18 , $32-33$.

Gennaro, Alfonso R., et al. (1990). Remington's Pharmaceutical Science (18 ${ }^{\text {th }}$ ed.). Pennsylvania, Mack Publishing Company.

Janssens, S., de Armas HN., Remon, JP., \& Van den Mootera, G. (2007). The use of a new hydrophilic polymer, Kollicoat $\mathrm{IR}^{\circledR}$, in the formulation of solid dispersions of Itraconazole, European Journal of Pharmaceutical Sciences, 30, 288 - 294. 
Leuner, C. \& Dressman, J. (2000). Improving drug solubility for oral delivery using solid dispersion. European Journal Pharmaceutics and Biopharmaceutics, 50, $47-60$.

Parfitt, K. (1999). Martindale: The Complete Drug Reference (vol.1). London, Pharmaceutical Press.

Saifullah, T.N. (2008). Teknik Peningkatan Disolusi dan Bioavailibilitas. Yogyakarta, Universitas Gajah Mada.

Serajuddin, ATM. (1999). Solid dispersion of poorly water-soluble drugs: Early Promises, Subsequent Problems and Recent Breakthroughs. Journal of Pharmaceutical Science, 351.

Shargel, L., Yu A. (2005). Biofarmasetika dan Farmakokinetika Terapan(edisi kedua). Surabaya, Airlangga University Press.

Tan H., Tjay dan Raharja K. (1986). Obat-obat Penting, Khasiat, Penggunaan, dan Efek-efek Sampingnya (edisi IV). Jakarta, Departemen Kesehatan Republik Indonesia. 